\title{
Predicting Normal Tissue Complications In Radiotherapy
}

\author{
Mohammad Omar Alsubael,
}

Department of Radiological Sciences, College of Applied Medical Sciences, King Saud University, (Saudi Arabia).

\section{Introduction}

Patient-to-patient variations in the radiosensitivity of normal and neoplastic tissues are well known and recognized both in vivo ${ }^{(1.2)}$ and in vitro studies. ${ }^{(3.6)}$ The typical example is the autosomal recessive disease ataxia-telangiectasia (AT). ATM patients are extremely sensitive to ionizing radiation. The patients develop severe to fatal radiation reactions when treated by standard radiotherapy regimens. Between those and normally sensitive patients, there is a wide range of radiosensitivity. These differences in the response to trcatment raised the possibility of individualizing the dose prescription. Therefore, considerable interest in the development of predictive assays have emerged. The predictivc test should have acceptable accuracy to enable screening between patients on the basis of their radiosensitivity in order to tailor the radiotherapy treatment to their expected clinical response.

Even though predicting the tumor response to radiotherapy has been attempted by many studies, ${ }^{(2.8)}$ this review will be limited to studies that are concerned with predicting the radiation effects on normal tissues. The tolerance of normal tissues is what actually constitutes the limiting factor for dose escalation in radiotherapy. Also, the concept of tumor resistance is relative since the tolerance of normal tissues prevents increasing the radiation dose to control the tumor. ${ }^{(9)}$ Therefore, a better knowledge of normal tissue tolerance would appear critical in the scarch for improving the efficacy of radiotherapy and to increase the therapeutic ratio. The objective is to tailor radiotherapy treatment to each individual patient's radiosensitivity. Radiation doses could be rcduced for the small radiosensitive subset of patients (about $5 \%)^{(10)}$ and increased for the more resistant once. This dose modulation is expected to increase local control while reducing radiotoxicity or at least keeping it to an acceptable level ${ }^{(11.12)}$ Although many factors such as the volume of normal tissuc involved in the irradiated area, the total dose received, the fractionation regimen, age, medication, the presence of an associated disease (ancmia, diabetes, hypertension, etc.), and chemothcrapy could influence the severity of reactions to radiotherapy, ${ }^{(13-15)}$ large parts of inter patients variability remain unexplained. Studying breast cancer patients, Turesson et al. ${ }^{(14)}$ estimated that such factors would only account for $30 \%$ of the total patient-to-patient variability. The remaining variability has been attributed to individual differences in cellular radiosensitivity, partly determined by genctic variations and partially by unknown cpigenetic factors.

\section{Radiosensitivity and predictive assays}

'I'he evaluation of normal tissue radiosensitivity of cancer patients before the start of treatment could improve radiotherapy results by prescribing the optimal dose for tumor cure without exceeding normal tissuc tolerance. Although the relationship between acute and late normal tissue reactions is a matter of controversy, late effects are really the dose-limiting factor in radiotherapy because they are irreversible and usually impair quality of life. (16.17) These include for example, fibrosis, telangiectasia, necrosis, fistula formation, nonhealing ulceration, and damage to specific organs, such as spinal cord, lung, blindness, etc. The mechanisms of these phenomena are not fully understood, however cell depletion of the tissue renewal units seems to be an important factor. Cell to cell communication may also contribute to the spread of these reactions. ${ }^{(18)}$ On the other hand, acute effects of radiotherapy such as reactions of the skin or oral mucosa are now of minor importance as modern computer-aided treatment planning techniques and the use of linear accelerators have led to lowering radiation doses at 
the beam entrance site.

In addition these reactions are usually noticed during the radiotherapy course and treatment plan is adjusted in order to minimize them. Acute radiation damage also tends to heal as soon as treatment ends.

Rarc reports of patients for whom radiation doses were adapted to their normal tissue radiosensitivity can be found in the literature. Hali et $a{ }^{(19)}$ reported an 11-year-old boy with medulloblastoma and AT. the radiosensitivity of the patttient's lymphoblastoid cells was measured in vitro and found to be 3 folds more sensitive than the normal. There fore, the patient was treated using one-third of the normal dose of standard radiotherapy regimen. Following treatment, the tumor regressed completely and acute and late normal tissue reactions were within the normal limits observed in non-AT patients. Another case was reported by Alsbeih et al. ${ }^{(20)}$ who described a 3year-old patient with astrocytoma associated with a family history of radiosensitivity and a chromosomal fragility syndrome not related to AT. The radiation oncologists were prompted to reduce the radiation dose to about $80 \%$ of what is usually prescribed in a standard protocol. The patient tolerated the treatment very. well with no side effects. Studying skin fibroblasts in-vitro evidenced the presumed hypersensitivity of the patient since they showed 2 fold increase in sensitivity to radiation as compared to normal. These two reports show that severe reactions can be avoided in hypersensitive patients by reducing the dose with no obvious deleterious consequences on tumor control. In contrast, many reports described patients who developed fatal reactions following unadapted radiotherapy treatment. ${ }^{(21-24)}$ This is in addition to the more frequent cases of patients developing serious late radiotoxicity. Furthermore, some hypersensitive patients could manifest severe acute reactions during the course of radiotherapy that necessitatc interruption of treatment. Conversely, it has been estimated that a significant proportion of patients would be more radioresistant than the average. Those patients would tolerate higher doses that would translate to better tumor control. ${ }^{(11.12)}$

A predictive assay will be based on taking a biopsy of normal cells from cancer patients prior to the start of the radiation treatment and determining their radiosensitivity in-vitro. The treatment can then be adjusted based on the degree of sensitivity of these normal cells. The choice of cell type to be used in an assay is important. Three cell types have been examined: skin fibroblasts, peripheral blood lymphocytes and keratinocytes. Fibroblasts and lymphocytes from hundreds of patients have been studied. Only fibroblasts gave reproducible results and a higher degree of correlation with the clinical outcome. In fact, fibroblasts are an important constituent of connective tissue, which is ubiquitous in the body and always involved in the irradiated areas.

'Therefore, fibroblasts are good candidate cells to evaluatc the general radiosensitivity of normal tissue and to compare between individuals. They are easy to establish and to culture in vitro. Their role in radio-fibrosis is uncontestable and illustrated by their scarcity in the irradiated field, which leads to slowing down the renewal of collagen molecules and their incomplete resorption. The accumulation of collagen molecules favors their crosslinking leading to loss of elasticity and the formation of fibrosis. ${ }^{(16)}$

\section{Measuring Radiosensitivity by CIonogenic Assay}

When tested in-vitro, fibroblasts from normal individuals and patients with a varicty of genetic diseases show a wide rangc of intrinsic radiosensitivity. ${ }^{(25.28)}$ Many studies examined a possible correlation between the in-vitro radiosensitivity, as measured by clonogenic assays, of skin fibroblasts and the clinical expression of normal tissue complications after radiotherapy.

Although a general consensus is premature at this stage ${ }^{(31)}$ it could safely be concluded that late complications of radiotherapy are associated with increased fibroblast radiosensitivityin-vitro.

Concerning acute reactions, there may be an association in the extreme cases of sensitivity. Rather unanimously, all the retrospcctive studies showed such a correlation or a trend toward a correlation, ${ }^{(32)}$ However, prospective studics showed mixed results ${ }^{(33.34)}$ Even so, there is in the literature enough positive evidence to conclude that genetic differences in cellular radiosensitivity contribute to the extent of normal tissue reactions to radiotherapy. The other important conclusion is that the actual measurement of radiosensitivity using, clonogenic assay has little chance of working in large-scale clinical screening. It is time consuming and very imprecise to be used with confidence as a predictive assay. Thus, a different approach is required if the goal of predicting normal tissue response is to be achieved. 
DNA Double-strand Breaks Ds Bs Determinant of Radiosensitivity

Since the early days of radiobiology, DNA damage has been recognized as the most important injury inflicted by ionizing radiation on living cells. Between the different types of DNA damage induced, double-strand breaks (dsbs) are those most associated with biological consequences. Unrepaired dsbs are likely to impair cell survival and if rejoined incorrectly can give rise to chromosome rearngements and deletions. Therefore, they can potentially cause cell lethality, mutagenesis and carcinogenesis.

Early attempts to correlate the radiosensitivity of human cells to DNA dsbs have used the neutral filter elution technique (NFE). Normal and tumor cell lines were tested but mixed results were obtained, mainly because of non-reproducibility related to technical biases. ${ }^{(35.36)}$ DNA dsbs were then studied using the pulsed-field gel electrophoresis (PFGE) technique that quickly replaced NFE. More consistent results were obtained particularly with normal human cclIs where radiosensitivity was correlated with the DNA dsbs remaining unrepaired 24 hours after radiation. ${ }^{(37.39)}$ As an example, the radiosensitivities of AT homozygous and $\mathrm{A}^{\prime} \mathrm{T}$ heterozygous (A TH) fibroblasts have been differentiated from each other based upon the number of residual lesions remaining after low dose. rate irradiation that totaled hundreds of grays ${ }^{(40)}$ These results also correlated with the survival data generated on these same ccll lines. A number of studies evaluated the relationship between normal tissue reactions to radiotherapy and dsbs induced in genomic DNA. ${ }^{(41.42)}$ Although these studies have linked residual dsbs with cell survival and/or late radiotoxicity, the assay lacked the required sensitivity to distinguish with confidence between sensitive and normal cell lines and therefore it cannot be used as a predictive assay. In addition, the assay measures the total dsbs but does not give any idea about the quality of the rejoined (i.c. ligated) ends. Therefore, classical PFGE results were only regarded as indicative of DNA dsbs repair deficiencies in comparative studes. Similar conclusions were reached using the Comet 41 and the micronuclei assays. ${ }^{(43.44)}$

\section{DNA Repair Mechanisms and Cellular Radiosensitivity}

The observation that some radiosensitive cell lines sustain a higher level of residual DNA dsbs after irradiation lends support to the hypothesis that genetic defects in DNA repair mechanisms could underlie the causes of differences in radiosensitivity between cell lines and between patients. In fact, a number of mammalian cell lines have been shown to be sensitive due to defective repair of $\mathrm{dsbs}^{(45.46)}$ and, where radioresistance was restored by genetic means dsb rejoiningfunction also returned. ${ }^{(47)}$ Recent advances in molecular biology allowed the identification of important genes that contribute to human radiosensitivity and predispose to cancer such as ATM, NBS, hMREII, LIG4, BRCA1 and BRCA2. The products of these genes are involved directly or indirectly in DNA repair. FU11hennore, a subset of patients with the severe combined immunodeficiency (SCID) condition, attributed to a V(D)J [variable( division)joining] recombination defect, demonstrate also an increased radiosensitivity invitro. ${ }^{(48)}$ These advances allow predictive assays bascd on DNA repair to be carried out at the mechanistic levels by trying to identify the protein(s) responsible for the defective signals or repair pathways that could lead to alteration in radiosensitivity. There are two major pathways for DNA dsb repair that have been identified in human cells: non-homologous end joining (NHEJ), and homologous recombination (HR).

Non-homologous end joining (NHEJ) pathway is considered the major pathway of dsb repair in mammalian cells. Repair is achieved without the presence of extensive homology between the DNA cnds to be joined. One major player in this repair pathway is the DNA-dependent protein kinase (DNA-PK). It is a primary DNA damage recognition system and it is expressed in constitutively high steady-state levels. Defects in the DNA-PK components confer radiosensitivity and $\mathrm{dsb}$ repair deficiency as was demonstrated in rodent mutant ccll lines. Cells from radiosensitive, cancer-prone $B A L B / c$ mice showed a significant reduced expression level of the catalytic subunit of DNA-PK (DNA-PKes) as well as a lowered DNAPK activity level accompanied by inefficient end joining of dsbs as compared with cells from all of the other common y use strams. ${ }^{(49)}$

The other repair system is known as homologous recombination (HR) pathway. Cells are believed to perform mitotic recombination and 'preferentially repair dsbs by $H R$ in late $S$ and $G 2$ phases of the cell cycle when an undamaged sister chromatid is available. In yeast, HR requires the $\operatorname{Rad} 51, \operatorname{Rad} 52$, Rad54, and Rad59 proteins in addition to Rad50, Mre 11 and Xrs2 which are also important. All these proteins have mammalian homologues. 
Human RAD5 I forms discrete foci in the nuclei of cells exposed to chemicals or ionizing radiation (but not UV). Over-expression of hRAD51 in human cells leads to a 2-3-fold increase in gene targeting (recombination between exogenous DNA and homologous chromosomal loci) and an enhanced resistance to ionizing radiation.5O Human cells are known to express two other RAD51-related proteins (Xrcc2 and Xrcc3) that interact with RAD51 and influence dsb repair by HR.51 Human RAD52 has a DNA double-strand end binding activit/ 2 and it probably co-operates with hRADSI in dsb repair.

\section{Other proteins involved in DNA repair}

Mutations in the ATM gene are responsible for the inheritance of the extremely radiation sensitive disease ataxia telangiectasia. ${ }^{(53)} \mathrm{AT}$ is an autosomal recessive disorder characterized by a variety of clinical symptoms and cellular abnormalities. In normal cells, the ATM protein is recruited to the site of the DNA dsbs and acts as a sensor for DNA damage. The recruitment may be activated by an unknown mechanism and induce a signal to stabilize p53 which. involves direct phosphorylation on serine 15 by the A TM, thereby regulating cell cycle. DNA replication, apoptosis, and DNA repair.

The fact that $\mathrm{AT}$ homozygous patients can readily be identified by the Physicians and that their Cancer treatment is usually tailored to their radiosensitivity makes AT heterozygosity more important in terms of predictive testing for radiosensitivity. It has been estimated that approximately $1 \%$ of the general population could be heterozygous for A TM gene mutations.

AT heterozygotes are clinicaJly asymptomatic, though they display in-vitro different levels of radiosensitivity when compared with normal individuals, although not as pronounced as in AT patients. ${ }^{(56)}$ Accordingly, it may be expected that asubstantial proportion of radiosensitive patients could be AT heterozygotes. Many groups of researchers studied this possibility particularly in breast cancer patients. ${ }^{(57-60)}$ Although these studies did not exclude a causative role for AT heterozygosity in the radiosensitivity of certain breast cancer patients and the risk of developing breast cancer, it would appear that the proportion of AT heterozygotes is less than the expected $4 \%$.

However, the importance of the A TM protein in the radiosensitivity to ionizing radiation and its multi-interactions with other proteins put the
ATM protein at the front of candidate causes leading to differences in radiosensitivity between radiotherapy patients.

Cells from patients with the rare autosomal recessive disorder called Nijmegen breakage syndrome (NBS) have also been found to be hypersensitive to radiation ${ }^{(61,62)}$ NBS 1 protein (also called Nibrin) is lost in NBS patients as judged by Western blotting $^{(63)}$ Stewart et at. ${ }^{(64)}$ described mutations in hMRE 11 gene located at $11 \mathrm{q} 21$, but not in A TM in certain individuals with a disorder virtually indistinguishable from AT. The cellular features resulting from these hMRE 11 mutations are similar to those seen in AT as well as NBS and include hypersensitivity to ionizing radiation, radioresistant DNA synthesis, genetic instability, and abrogation of ATM-dependent cell cycle checkpoints. The hMRE 11 hRAD50/ NBS1 complex has been proposed to act as a sensor of DNA damage.

The majority of hereditary forms of breast and ovarian cancers can be accounted for by gennline muations in two human breast cancer susceptibility genes, BRCA1 and BRCA2. These are invotved in DNA repair in addition to other functions. Loss of functional BRCA1 results in moderate sensitization to radiation and DNAdamaging chemicals. ${ }^{(65.66)}$ BRCA2 cells are also sensitive to DNA-damaging agents, although more pronounced to ultraviolet (UV) than y-radiation. ${ }^{(67)}$ Although BRCA1 and BRCA2 cel1s showed DNA repair deficiency and increased radiosensitivity invitro the presence and the impact of $\mathrm{BRCAl}$ and BRCA2 protein alterations (expression, activity) on patient sensitivity to radiotherapy in breast, ovarian and probably other malignancies remain to be explored.

The tumor suppressor protein p53 plays a central role in controlling the cellular DNA damage response following exposure to DNA damaging agents such as ionizing radiation, $U V$ radiation and DNA alkylating agents. ${ }^{(68)}$ It determines the fate of cells in which dsbs persist.

Alterations in the p53 gene may occur as germline mutations in some cancer-prone families as part of Li-Freullleni syndrome, and also as somatic mutations in about $50 \%$ of human tumors. p53 is a transcription factor that binds to sequencespecific sites in the promoter region of several genes, such as W AFI/CIP1, mdin2, WIP1, GADD45, ba:c and IGF-BP3. The transcriptional activation of these p53 target genes is associated with cell cycle arrest, DNA repair or apoptosis. ${ }^{(6)}$ The $\mathrm{p} 53$ protein also represses transcription of a 
number of cellular genes with promoters lacking p53 binding sites, such as c-fos, c-jun, Rb and bcl$2{ }^{\left({ }^{(68)}\right.}$ Finally, several other gene products such as $\mathrm{c}$ $\mathrm{Abl}, \mathrm{IRF}-\mathrm{I}$ and INGl (p33) - have recently been shown to be involved in the p53-mediated DNA damage response to ionizing radiation. Mutations in these genes can confer sensitivity to ionizing radiation or predisposition to cancer or both. Therefore, several of these genes may also be the underlying cause of sensitivity in at least a proportion of the radiosensitive patients and need to be investigated in the near future.

\section{Conclusion}

The idea of developing an assay for predicting normal tissue complications in radiotherapy is under intensive research in many laboratories around the world. An ideal assay is that which will avoid the drawbacks of the classical cIonogenic survival method, including mainly the time consumption. Advances in molecular biology have introduced techniques that can potentially facilitatc the development of an assay which can be used in routine radiotherapy.

Hopefully, the mechanism(s) responsible for the increased radiosensitivity and risk to develop severe complications will be identified, in addition to the ability of screening patients according to radiosensitivity.

\section{References:}

1. 'Thcker SL, 'Turesson I, Thames HD. Evidence for individual differences in the radiosensitivity of human skin. Eurpean Journal of Cancer. 1992;28A(11): 1783-1791.

2. Geara FB, Komaki R, Tucker SL, et al. Factors influencing the development of lung fibrosis after chemoradiation for small cell carcinoma of the lung: evidence for inherent interindividual variation. International Journal of Radiation Oncology, Biology and Physics. 1998;41 (2):279286.

3. Fertil B, Malaise EP. Inherent cellular radiosensitivity as a basic concept for human tumor radiotherapy. intemational Joumal of Radiation Oncology, Biology and Physics. 1981 ;7(5):621629.

4. Deacon J, Peckham MJ, Steel GG. The radioresponsiveness of human tumours and the initial slope of the cell survival curve. Radiotherapy and Oncology. 1984;2(4):317-323.

5. Girinsky $T$, Bernheim $A$, Lubin $R$, et a!. In vitro parameters and treatment outcome in head and neck cancers treated with surgery and/or radiation: cell characterization and correlations with local control and overall survival.
International Jounal of Radiation Oncology, Biology and Physics.1994;30(4):789-794.

6. West CM, Davidson SE, Burt PA, et al. The intrinsic radiosensitivity of cervical carcinoma: correlations with clinical data. International Journal of Radiation Oncology, Biology and Physics. 1995;31 (4):841-846.

7. Crompton NEA OM, Larsson B, LuetolfUM. Theory and Practice of Predictive Assays in Radiation Therapy. Strahlentherapie und Onkologie. 19971997; 173(2):58-67.

8. Corvo R, Antognoni P, Sanguineti. G. Biological predictors of response to radiotherapy in head and neck cancer: recent advances and emerging perspectives. [Review] [69 refs]. Tumori. 2001;87(6):355-363.

9. Peters LJ. Radiation therapy tolerance limits. For one or for all? Cancer. 1996;77(11):2379-2385.

10. Norman A, Kagan AR, Chan SL. The importance of genetics for the optimization of radiation therapy. A hypothesis. American Journal of Clinical Oncology. 1988; $11(1): 84-88$.

11. Tucker SL, Geara FB, Peters LJ, et al. How much could the radiotherapy dose be altered for individual patients based on a predictive assay of normal-tissue radiosensitivity? Radiotherapy and Oncology. 1996;38(2):103-113.

12. Mackay RI, Hendry JH. The modeled benefits of individualizing radiotherapy patients' dose using cellular radiosensitivity assays with inherent variability. Radiotherapy and Oncology 1999;50( 1):67-75.

13. Turesson I. Individual variation and dose dependency in the progrcssion rate of skin telangiectasia. International Joural of Radiation Oncology, Biology and Physics. 1990; 19(6): 15691574.

14. Turesson I, Nyman J, Holmberg E, et al. Prognostic factors for acutc and late skin reactions in radiotherapy patients. International JOllmal of Radiation Oncology, Biology and Physics. 1996;36(5): 1065-1 075.

15. Simonen P, Hamilton C, Ferguson S, et a!. Do inflammatory processes contribute to radiation induced erythema observed in the skin of humans? Radiotherapy and Oncology. 1998;46(1 ):73-82.

16. Tubiana M, Dutreix J, Wambersie A. Radiobiologie. Tours: Hermann; 1986.

17. Hellman S. Principle of Cancer Management: Radiation Therapy. In: DeVita V, Hellman S, Rosenberg S, eds. Cancer: Principles and Practice of Oncology. 5th ed. Philadelphia: LippincottRaven; 1997:307-235.

18. Dorr W, Engenhart-Cabillic R, Zimmermann JS. Normal tissue reactions in radiotherapy and oncology. Introduction. Frontiers of Radiation Therapy \& Oncology. 2002; 37: IX-XIl I. 2002;37:DXXIII. 
19. Hart RM, Kimler BF, Evans RG, et al. Radiotherapeutic management of medulloblastoma in a pediatric patient with ataxia telangiectasia. International journal of Radiation Oncology, Biology and Physics. 1987;13(8):1237-1240.

20. Alsbeih G, Story M, Maor M, Geara F, Brock W. Chromosomal fragility syndrome and family history of radiosensitivity as indicators for radiotherapy dose modification. Radiotherapy and Oncology. $2003 ; 66: 341-344$.

21. Cunliffe PN, Mann JR, Cameron $\mathrm{AH}$, et al. Radiosensitivity in ataxia-telangiectasia. British Journal of Radiology. 1975;48:374-376.

22. Pritchard J, Sand land MR, Breatnach FB,et al. The effects of radiation therapy for Hodgkin's disease in a child with ataxia telangiectasia: a clinical, biological and pathologic study. Cancer. 1982;50(5):877-886.

23. Brown RC, Raaphorst GP, Danjoux CE, et al. Multiorgan fatal chronic complications following radiation treatment for cancer of the cervix: results of fibroblast assay. Gynecologic Oncology. 1996;61(1):116-121.

24. Burnet NG, Wurm R, Peacock JH. Low dose-rate fibroblast radiosensitivity and the prediction of patient response to radiotherapy. international Journal of Radiation Biology. 1996;70(3):289-300.

25. Taylor AMR, I-Iarnden DG, Arlett CF, et al. Ataxia-telangiectasia, a human mutation with abnormal radiation sensitivity. Nature. 1975;258:427-429.

26. Hannan MA, Greer W, Smith BP, et al. Skin fibroblast cell lines derived from non-Hodgkin'slymphoma (NHL) patients show increased sensitivity to chronic gamma irradiation. international Journal of Cancer. $1991 ; 47(2): 261$ 266.

27. Weeks DE, Paterson MC, Lange $K$, et al. Assessment of chronic gamma radiosensitivity as an in vitro assay for heterozygote identification of ataxia-telangiectasia. Radiation Research. 1991; 128( 1):90-99.

28. Alsbeih MG, Fertil B, Arlett C;F, et al. High splitdose recovery in hypersensitive human fibroblasts: a case of induced radioresistance? International Journal of Radiation Biology. 1996;69(2):225-239.

29. Weichselbaum RR, Epstein J, Little JB. in-vitro radiosensitivity of human diploid fibroblasts derived from patients with unusual clinical responses to radiation. Radiology. 1976; 121 :479482.

30. Russell NS, Grummels A, Hart AA, et al. Low predictive value of intrinsic fibroblast radiosensitivity for fibrosis development following radiotherapy for breast cancer. International Journal of Radiation Biology. 1998;73(6):661-670.
31. Bentzen SM, Hendry JI-I. Variability in the radiosensitivity of normal cells and tissues. Report from a workshop organised by the European Society for Therapeutic Radiology and Oncology in Edinburgh, UK, 19 September 1998. International Journal of Radiation Biology. 1999;75(4):513-715.

32. Alsbeih G, Malone S, Lochrin C, et al. Correlation between normal tissue complications and in vitro radiosensitivity of skin fibroblasts derived from radiotherapy patients treated for variety of tumors. International Journal of Radiation Oncology, Biology and Physics. 2000;46(1): 143152.

33. Geara FB, Peters LJ, Ang KK, et al. Prospective comparison of in vitro normal cell radiosensitivity and normal tissue reactions in radiotherapy patients. International Journal of Radiation Oncology, Biology and Physics. 1993;27(5): 11731179.

34. Brock W A, Tucker SL. In-vitro radiosensitivity and normal tissue damage [editorial). Radiotherapy and Oncology. 2000;55(2):93-94.

35. Okayasu R, Iliakis G. Linear DNA elution dose response curves obtained in $\mathrm{CHO}$ cells with nonunwinding filter elution after appropriate selection of the lysis conditions. International Journal of Radiation Biology. 1989;55(4):569-581.

36. Radford IR. Lysis solution composition and nonlinear dose-response to ionizing radiation in the non-denaturing DNA filter elution technique. International Journal of Radiation Biology. 1990;57(3):479-483.

37. Foray N, Priestley A, Alsbeih G, et al. Hypersensitivity of ataxia telangiectasia fibroblasts to ionizing radiation is associated with a repair deficiency of DNA double-strand breaks. International Journal of Radiation Biology. 1997;72(3):271-283.

38. Zhou PK, Sproston AR, Marples B et al. The radiosensitivity of human fibroblast cell lines correlates with residual levels of DNA doublestrand breaks. Radiotherapy and Oncology. 1998;47(3):271-276.

39. Dikomey E, Dahm-Daphi J, Brammer I, et al. Correlation between cellular radiosensitivity and non-repaired double- strand breaks studied in nine mammalian cell lines. International Journal of Radiation Biology. 1998;73(3):269-278.

40. Blocher D, Sigut D, Hannan MA. Fibroblasts from ataxia telangiectasia (AT) and AT heterozygotes show an enhanced level of residual DNA doublestrand breaks after low dose-rate gammairradiation as assayed by pulsed field gel electrophoresis. International Journal of Radiation Biology 199] ;60(5):791-802.

41. Sarkaria IN, Bush C, Eady JJ, et al. Comparison between pulsed-field gel electrophoresis and the comet assay as predictive assays for 
radiosensitivity in fibroblasts. Radiation Research. 1998; 150(1): 17-22.

42. Dikomey E, Brammer I, Johansen J, et al. Relationship between DNA doublestrand breaks, cell killing, and fibrosis studied in confluent skin fibroblasts derived from breast cancer patients. International Journal of Radiation Oncology, Biology and Physics. 2000;46(2):481490.

43. Johansen J, Streffer C, Fuhrmann C, et al. Radiosensitivity of normal fibroblasts from breast cancer patients assessed by the micronucleus and colony assays. International Journal of Radiation Biology 1998;73(6):671-678.

44. Barber JB, Burrill W, Spread borough AR, et al. Relationship between in-vitro chromosomal radiosensitivity of peripheral blood lymphocytes and the expression of normal tissue damage following radiotherapy for breast cancer. Radiotherapy and Oncology 2000;55(2): 179-186.

45. Jeggo P A, Kemp UvI. X-ray-sensitive mutants of Chinese hamster ovary cell line. Isolation and cross-sensitivity to other DNA-damaging agents. Mutation Research. 1983; 112(6):3] 3-327.

46. Kysela BP, Michael BD, Arrand JE. Relative contributions of levels of initial DNA damage and repair of double strand breaks to the ionizing radiation-sensitive phenotype of the Chinese hamster cell mutant, XR- V15B, Part 1. X-rays. International Journal of Radiation Biology 1993;63(5):609616.

47. Jeggo $P \Lambda$, Hafezparast $M$, Thompson AF, et al. Localization of a DNA repair gene (XRCC5) involved in double-strand- break rejoining to human chromosome 2. Proceeding of the National Academy of Science USA. 1992;89(14):6423-6427.

48. Peake J, Waugh A, Le Deist F, et al. Combined immunodeficiency associated with increased apoptosis of Iymphocytes and radiosensitivity fibroblasts. Cancer Research. 1999;59( 14): 34543460 .

49. Okayasu R, Suetomi K, Yu Y, et al. A deficiency in DNA repair and DNA-PKcs expression in the radiosensitive $\mathrm{BALB} / \mathrm{c}$ mouse. Cancer Research. $2000 ; 60(16): 4342-4345$.

50. Yanez RJ, Porter AC. Gene targeting is enhanced in human cells overexpressing hRAD51. Gene Thempy. 1999;6(7): 1282-1290.

51. Liu N, Lamerdin JE, Tebbs RS, et al. XRCC2 and XRCC3, new human Rad51-family members, promote chromosome stability and protect against DNA cross-links and other damages. Molecular Cell. 1998;1(6):783-793.

52. Van Dyck E, Stasiak AZ, Stasiak A, et al. Binding of double-strand breaks in DNA by human Rad52 protein. Nature. 1999;398(6729):728-731.

53. Savitsky K, Bar-Shira A, Gilad S, et al. A single ataxia telangiectasia gene with a product similar to PI-3 kinase. Science. 1995;268(5218):1749-1753.
54. Easton DF. Cancer risks in A- T heterozygotes. International Journal of Radiation Biology 1994;66(6 Suppl):S177-182.

55. Triki C, Feki I, Meziou M, et al. [Clinical, biological and genetic study of 24 patients with ataxia telangiectasia from southern Tunisia]. Rev Neurol (Paris. 2000; 156(6-7):634637.

56. Murnane JP, Kapp LN. A critical look at the association of human genetic syndromes with sensitivity to ionizing radiation. Seminars in Cancer Biology. 1993;4(2):93-104.

57. Ramsay J, Bin"ell G, Lavin M. Breast cancer and radiotherapy in ataxia-telangiectasia heterozygote [letter]. Lancet. 1996;347(9015):1627.

58. Nichols KE, Levitz $\mathrm{S}$, Shannon $\mathrm{KE}$, et al. Heterozygous germ line A T'M mutations do not contribute to radiation- associated malignancics after Hodgkin's disease. Journal o.f Clinical Oncology 1999;17(4):1259.

59. Scott D. Chromosomal radiosensitivity, cancer predisposition and response to radiotherapy. Strahlenthempie Onkologie. 2000; 176(5):229234.

60. Angele S, Hall J. The A 'I'M gene and breast cancer: is it really a risk factor? Mutation Research. 2000;j62(2-3): 167-178.

61. Weemaes CM, Hustinx TW, Scheres JM, et al. A new chromosomal instability disorder: the Nijmcgen breakage syndromc. Acta Pacdiatr Scand.1981;70(4):557-564.

62. van der Burgt I, Chrzanowska KH, Smeets D, et al. Nijmegen breakage syndrome. J Med Gene!. 1996;33(2): 153-156.

63. Maser RS, Monsen KJ, Nelms BE, et al. hRad50 nuclear foci are induced during the normal cellular response to DNA double-strand breaks. Moleclllar Cell Biology. 1997; 17( I 0):6087-6096.

64. Stewart GS, Maser RS, Stankovic 'T', et al. The DNA double-strand break repair gene hMRE 11 is mutated in individuals with an ataxiatelangiectasia-like disorder. Cell. 1999;99(6):577587.

65. Gowen LC, A vrutskaya A V, Latour $\Lambda M$, et al. BRCA 1 required for transcriptioncoupled repair of oxidative DNA damage. Science. 1998;281 (5379): $1009-10] 2$.

66. Foray $\mathrm{N}$, Randrianarison $\mathrm{V}$, Marot $\mathrm{D}$, et al, Gamma-rays-induced death of human cells carrying mutations of BRCA1 or BRCA2. Oncogene. 1999; 18(51'):7334-7342.

67. Gaffney OK, Brohet RM, Lewis CM, et al. Response to radiation therapy and prognosis in breast cancer patients with BRCA 1 and BRCA2 mutations. Radiotherapy and Oncology. 1998;47(2): 129136.

68. Ko LJ, Prives C. p53: puzzle and paradigm. Genes and Development. 1996; $10(9)$ : 1054-] 072.

69. Fiscella M, Zhang H, Fan S, et al. Wip I, a novel 
human protein phosphatase that is induced in response to ionizing radiation in a p53dependent manner. Proceeding of the National
Academy of Science USA. 1997;94(12):60486053. 